\title{
Application of the resonant energy separation effect at natural gas reduction points in order to improve the energy efficiency of the gas distribution system
}

\author{
Andrei M. SCHIPACHEV, Alena S. DMITRIEVA $\triangle$ \\ Saint Petersburg Mining University, Saint Petersburg, Russia
}

How to cite this article: Schipachev A.M., Dmitrieva A.S. Application of the resonant energy separation effect at natural gas reduction points in order to improve the energy efficiency of the gas distribution system. Journal of Mining Institute. 2021. Vol. 248, p. 253-259. DOI: 10.31897/PMI.2021.2.9

\begin{abstract}
Maintaining the gas temperature and the formation of gas hydrates is one of the main problems in the operation of gas pipelines. Development and implementation of new effective methods for heating the gas during gas reduction will reduce the cost of gas transportation, solve the problem of resource and energy saving in the fuel industry. Study is aimed at increasing the energy efficiency of the natural gas reduction process by using a resonant gas heater to maintain the set temperature at the outlet of the gas distribution station (GDS) and prevent possible hydrate formation and icing of the station equipment. Paper considers the implementation of fireless heating of natural gas and fuel gas savings of heaters due to the introduction of a thermoacoustic reducer, operating on the basis of the Hartmann - Sprenger resonance effect, into the scheme of the reduction unit. By analyzing the existing methods of energy separation and numerical modeling, the effectiveness of the resonant-type energy separation device is substantiated. Modification of the reduction unit by introducing energy separating devices into it will allow general or partial heating of natural gas by its own pressure energy. Developed technology will allow partial (in the future, complete) replacement of heat energy generation at a gas distribution station by burning natural gas.
\end{abstract}

Key words: natural gas; gas pipeline; energy saving; energy separation; natural gas heating; Hartmann - Sprenger effect; reduction; gas distribution station

Introduction. Nowadays, Russia has developed and implemented programs to improve the application efficiency of the fuel and energy resources (FER) and resource saving, including reduction of natural gas losses $[21,22,33]$.

Long gas transportation distances cause high pumping pressure, which must be lowered before shipment to the consumer. Lowering of the pressure occurs at the reduction points by spending the energy of natural gas flow to overcome the local resistance, represented by the throttle part of the pressure regulator [32].

Natural gas transport and distribution networks are extensive and branched systems with many points for gas pressure reduction (PRG), protection of gas pipelines from corrosion and electrochemical protection units (EPU). The main purpose of the PRG is to lower the high pressure (at which gas is transported over long distances) to the level required by consumers, and then maintain it at this level.

Energy possessed by the gas flow is partially lost during reduction, when the gas temperature decreases and, therefore, it becomes necessary to heat it up. Energy can be efficiently converted into other types of energy: electrical energy for the needs of the gas distribution station itself and/or heat energy for leveling gas cooling during throttling.

Since the 30s in the XX century, in the USA, Britain, Canada, Russia and other countries, research is being carried out in the field of utilizing gas pressure energy. In Russia, there are state programs that stimulate the development and implementation of energy-saving systems [12].

Research object of the article is the natural gas reduction unit in a gas distribution station. Study is aimed at solving the problem of reducing the amount of fuel gas consumed to restore the temperature of the natural gas flow, which decreases when it is reduced. According to GOST 5542-2014, gas temperature at the outlet of the reduction point must exceed the dew point temperature that is in the range of $-7 \ldots-12{ }^{\circ} \mathrm{C}$ and depends on the gas temperature, pressure and humidity. Flow rate of gas after the reduction point changes during the year, week, day and one 
hour. On average, the highest flow rate exceeds the lowest one during the month by 2.5 times, during the week - by 1.2 times, and during the day - by 1.8 times. These ratios indicate the nonstationary process of the gas movement in the gas distribution network.

At GDS design stage, needs of the station for electricity and heat are assessed depending on its purpose, location conditions, area and size, calculated temperature in the cold season, accounting for standard snow and wind loads and other features. Installation of boiler units at GDS is a common solution to provide heat and electrical energy [25].

When natural gas is reduced, a sharp decrease in temperature occurs, and there is a risk of hydrate formation in the form of solid crystalline deposits on the walls of pipelines. Mainly, hydrates are formed in places of pipeline constriction, pressure regulators and measuring equipment [10]. Moreover, due to the significant cooling of the gas, icing of the pipeline fittings occurs.

Gas heaters, local heating of pressure regulator casings, and introduction of hydrate formation inhibitors into the gas stream (most often methanol) are used at gas distribution stations as measures to prevent freezing of equipment casings and the formation of hydrates [16]. The most widespread in practice is the first method, because the second has the lowest efficiency, and the third is costintensive $[10,16]$.

The main types of heaters are fire (heated by fire) and water (heated by hot water or steam) ones. The first type is dangerous in terms of fire safety, and the second requires more fuel consumption and labor for maintenance. For the operation of heaters, GDS is equipped with powerful boiler and power supply units, and sewerage installations. Requirements for the GDS operation prescribe the installation of at least two heaters (one in reserve). This natural gas heating system requires more energy than is consumed for the own needs of the gas distribution station $[12,25]$.
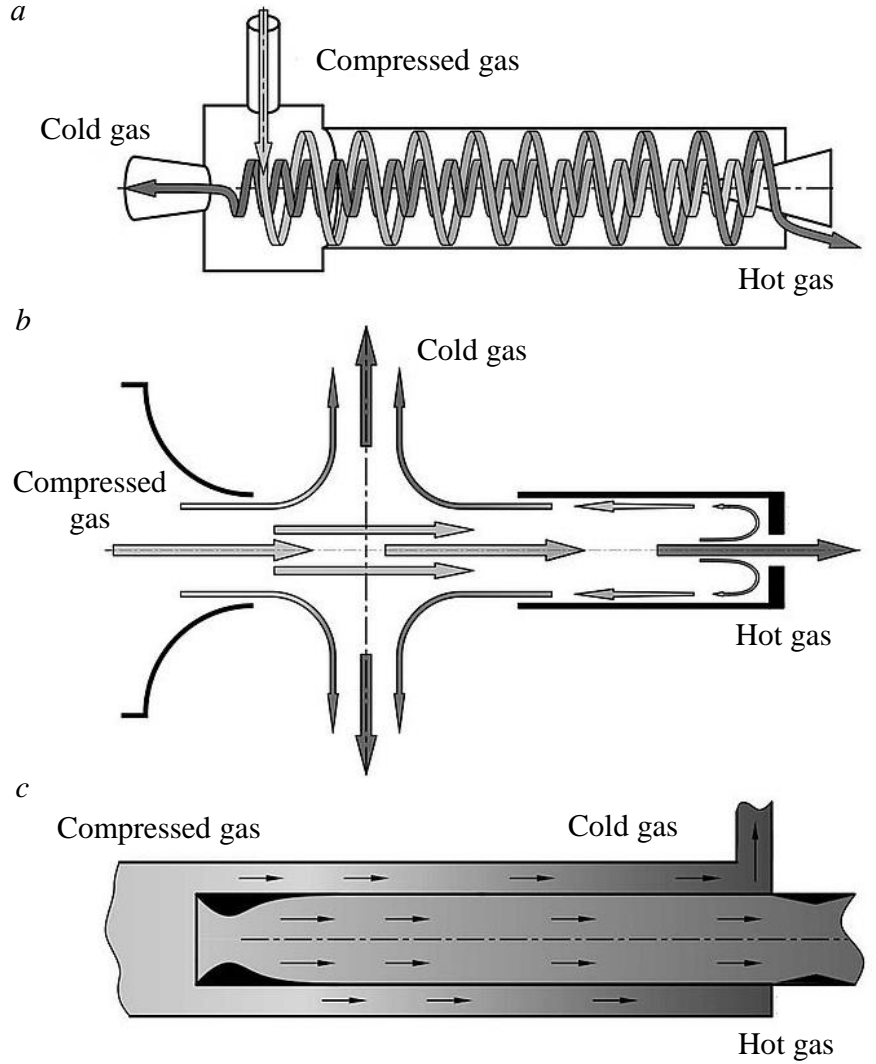

Fig.1. Devices for machineless energy separation (temperature separation) of a gas stream: $a$ - Rank - Hilsch tube; $b$ - Hartmann - Sprenger tube; $c$ - Leontiev tube [5]
Aim of the work is to implement fireless heating of natural gas and save fuel gas of heaters by introducing a thermoacoustic reducer, operating on the basis of the Hartmann - Sprenger resonance effect, into the scheme of the reduction unit. This solution is aimed at increasing the energy efficiency of the reduction process by using a resonant gas heater to maintain the set temperature value at the GDS outlet and prevent possible hydrate formation and icing of the station equipment.

Statement of the problem. In regard to the conditions of a gas distribution station, the utilization of natural gas energy during its reduction (Fig.1) [24, 27, 36] is carried out in different ways, for example, using a device based on the Rank - Hilsch vortex effect; temperature stratification using a Leontiev tube; expander generator sets; devices based on the Hartmann Sprenger effect.

As an example of a device operating on the vortex Rank - Hilsch effect, a pressure regulator with a heat generator RDU-T is taken. It is built into the regulator and 
heats the reducing unit of the pressure regulator using the kinetic energy of the gas [14, 23, 35]. During the process, hydrate formation and freezing of the unit is prevented at high pressure drops.

On the basis of temperature stratification using a Leontiev tube [7, 18], the author of [23] proposed a device for fireless heating and reduction of natural gas without the use of additional machines and equipment. The device works as follows. Gas flow is divided into two: one accelerates to supersonic speed in the Laval nozzle, the second - with high-pressure and subsonic speed, flows from the opposite side in the inter-wall space. In the process, the interaction of gas flows through the heat-conducting wall of the device takes place: the supersonic heated flow is directed to the gas distribution station, the cooled subsonic flow is directed to the compressor station [2, 28, 34].

If the pressure energy of the flow is used to rotate any expansion machine (expander), then this allows it to be utilized or directed to various useful needs [1]. Academician M.D.Millionshchikov proposed such use of the pressure in the trunk gas pipelines back in 1947. At present, expandergenerator units are used at gas-reducing points of trunk gas pipelines. Energy from the gas stream is converted to mechanical energy in the expander and electrical energy in the generator. Resulting electrical energy is spent on the needs of the gas-reducing point, including heating the gas after throttling $[1,19,29]$.

The Hartmann - Sprenger effect, discovered in the second half of the 20th century, consists in the fact that when a stationary air stream flows around cavities (tubes) of a certain depth, there are pulsations of gas pressure and an increase in the temperature of the cavities walls to values exceeding (by tens and sometimes hundreds of degrees) stagnation temperature in the incident flow [13]. This exceeding of temperature, which is unacceptable in the law of energy conservation, occurs as a result of unsteady shock-wave processes formed when the gas flowing around the open end of the cavity interacts with the volume of gas inside this cavity $[4,13,17]$. This effect was first discovered by Julius Hartmann.

Gas at the open end of the cavity excites oscillations, the frequency of which is equal to the frequency of the gas column in the separation region [13]. Oscillation frequency is at the same level due to the energy of the external gas flow $[4,13]$. Compression or expansion waves propagate into the cavity from the oscillating flow interface and are reflected when they collide with the closed end of the cavity. Compression waves interacting with each other at the entrance to the cavity generate a shock wave of finite amplitude. Its propagation in the gas flow leads to an increase in entropy, accompanied by irreversible heat release. Generated heat accumulates inside the closed end of the cavity, and the gas gradually warms up.

If the vibrations form due to flow breaks at the entrance to the closed cavity, the frequency of pressure oscillations will depend only on the length of the cavity $\left(l_{t}, \mathrm{~m}\right)$ and the speed of sound in the medium $(c, \mathrm{~m} / \mathrm{s})$ and will be $f=c / 2 l_{\mathrm{t}}[4,31]$.

Frequency at resonance will be two times less: when reflected from the open end of the cavity, the wave changes sign, the reflected shock wave will transform into an expansion wave. Therefore, the theoretical frequency of oscillations in resonance is $f_{\mathrm{t}}=c / 4 l_{\mathrm{t}}$.

When this effect occurs, final gas temperature depends on the conditions of heat transfer to the external free flow through the walls, as well as on the intensity of the mass exchange process in the region of the open end of the cavity $[3,15,31]$.

Application of the Hartmann - Sprenger effect is known in aircraft construction, at the oil fields, small-scaled production of liquefied natural gas (LNG) [13, 23]. It should be noted that this effect in the gas transportation system has not previously found application in the Russian Federation and abroad, as it was considered extremely negative.

Conducted assessment of the economic efficiency for the application of this effect at the points of natural gas reduction has shown a positive result and confirms the efficiency of investments in the development of reduction devices operating on the resonance effect. 


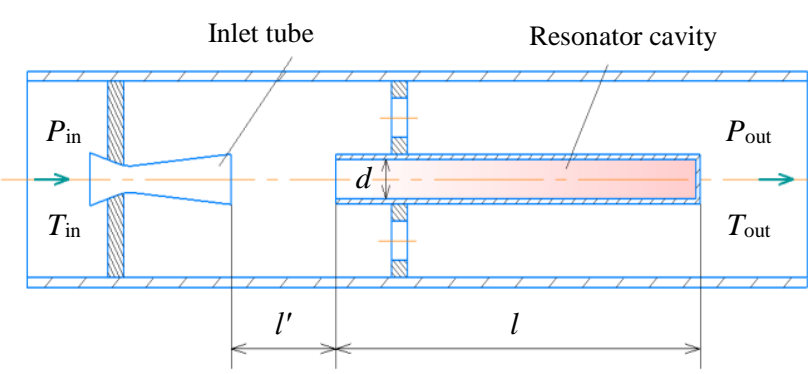

Fig.2. Devicegeometry

$P_{\text {in }}, T_{\text {in }}-$ inlet pressure and temperature; $P_{\text {out }}, T_{\text {out }}-$ outlet pressure and temperature; $l$ - length of resonator cavity; $l^{\prime}-$ distance between inlet tube and resonator cavity; $d$ - diameter of resonator cavity

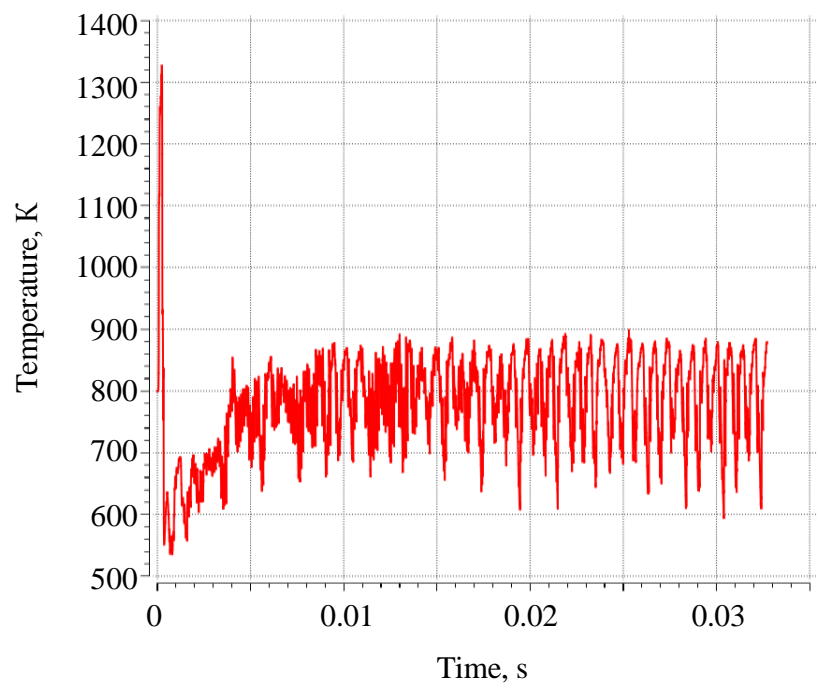

Fig.3. Plot of temperature pulsations at the base of the resonator

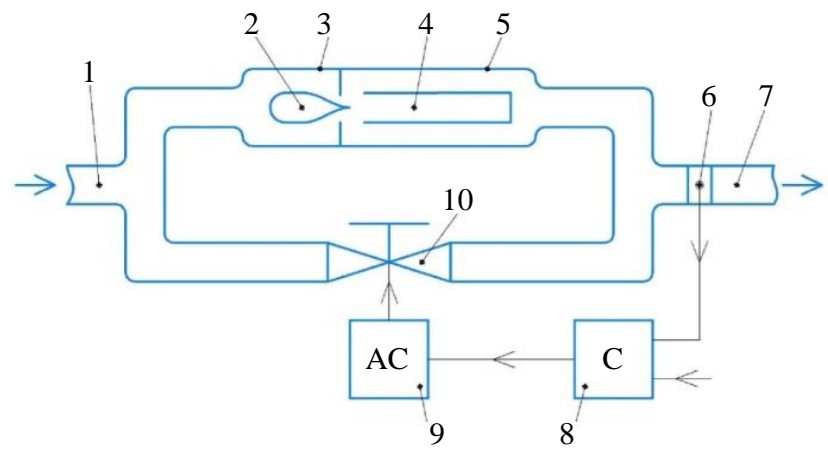

Fig.4. Schematic diagram of a device for unheated reduction of natural gas [20]
Methodology. Purpose of the simulation is qualitative obtaining of the Hartmann Sprenger resonance effect. Numerical analysis is performed by the finite element method in the Ansys Fluent software. Design model is built on the basis of the device geometry, intended for further fabrication of the structure and conducting experimental investigations (Fig.2).

Mesh area with high detailing of wall zones and zones with the highest gas flow velocity was constructed [30]. Air described by the Redlich - Kwong real gas law is taken as a gaseous medium $[6,8,26,31]$. At the input and output of the device model, boundary conditions are set: $P_{\text {in }}=600000 \mathrm{~Pa} ; P_{\text {out }}=0 \mathrm{~Pa}(\mathrm{ex}-$ cess pressure); $Q_{m}=0.0090375 \mathrm{~kg} / \mathrm{s}\left(187 \mathrm{~m}^{3} / \mathrm{h}\right.$ at standard conditions), ratio of temperatures $T_{\text {in }}$ and $T_{\text {out }}$ should not exceed 1.42 (adiabatic coefficient 1.4). Length of the resonator cavity is $73 \mathrm{~mm}$, its wall thickness is $2 \mathrm{~mm}$. Calculation was carried out on the basis of the DES turbulence model $[9,11,31]$.

Based on the results of numerical simulation, values of temperature oscillations were obtained at a point located in the lower part of the resonator (Fig.3).

Sought frequency of resonant oscillations is obtained using the Fourier transformations $1111 \mathrm{~Hz}$. Theoretical frequency of resonant oscillations is found: $f_{\mathrm{t}}=1133 \mathrm{~Hz}$. Deviation for the calculated frequency of resonant oscillations and theoretical frequency was $1.94 \%$, which indicates the correct compilation of the calculation model.

Discussion. Based on the analysis of natural gas energy utilization methods, a device for unheated and fireless natural gas reduction is proposed based on the Hartmann - Sprenger resonance effect (Fig.4). Device consists of a supersonic nozzle, a resonator coaxially located with it and a pressure regulator connected in parallel to compensate for daily and seasonal irregularities in gas flow rate.

Developed thermoacoustic pressure regulator contains a single flow-through frame 5 , inside which there are nozzle 3 with a central body 2 and a resonator 4 . Inlet and outlet of the frame 5 are connected, respectively, with the high 1 and low 7 pressure tubes, as well as with each other by a pipeline with a control valve 10 . Output of the pressure sensor 6 , installed at the output of the thermoacoustic regulator is connected to the input of the governing controller 8 , the output of which is connected to the input of the actuator 9 of the control valve 10 . 
The first stream, losing pressure and temperature, accelerates in nozzle 3 with central body 2 and flows onto the closed cavity of the conical resonator 4, exciting high-frequency shock waves that heat up the gas in it. Heated gas periodically outflows from the resonator 4 into the flowthrough path of the frame 5, which is united with the nozzle 3 . There it mixes with the low temperature gas flowing around the resonator 4, forming with it a gas stream of an average temperature, directed to mixing with the second gas stream separated earlier after the high-pressure inlet 6 .

High-pressure gas enters a nozzle designed for a specific pressure range. At the outlet of the nozzle, concentrated accelerated gas flow enters a resonator of a certain length coaxial with the nozzle, located at a certain distance from the nozzle. Hartmann - Sprenger effect arises in the resonator, as a result of which the gas heats up above the stagnation temperature. Cooling of gasduring throttling is leveled by its local heating in the resonator.

Maintaining the pressure at the outlet of the thermoacoustic regulator at a predetermined level, together with automatic regulation of the height of the nozzle 3 by its central body 2 , make it possible to ensure the stability of the thermoacoustic regulator, which depends on the constancy of the pressure drop across it. This ensures a high linearity of the temperature dependence at the outlet of the regulator on the flow rate through it and the reliability of the technological operation of reduction as a whole.

Based on the Competence Center for engineering and technology of field development in Arctic conditions (CC “Arktika") of Saint Petersburg Mining University the experimental setup was created according to the scheme (Fig.4), which has an additional temperature sensor installed at the base of the resonator inside the frame [20].

Experimental investigations have been carried out to test the simulation results and confirm the occurrence of the resonance effect and gas heating in the developed device. Conditions for the experiment considered the same pressures as in the numerical simulation. Working gas is air. As a result, a resonant oscillation frequency of $2000 \mathrm{~Hz}$ was achieved. Thus, the achievement of the Hartmann - Sprenger effect is confirmed. Experimental frequency of pressure oscillations differs from the theoretical by $12 \%$, which can be explained by the high concentration of oil in the air leaving the compressor and the variability of the pressure gradient.

Due to the small dimensions of the resonator, temperature sensor was not installed directly into the gas medium inside it, as this would cause additional difficulties in manufacturing. However, this solution led to an indirect determination of the air temperature inside the resonator.

Using the constructed model of the device in Ansys Fluent, gas temperature at the base of the resonator is determined. Initial data for numerical simulation, according to the obtained experimental values: $T_{\text {in }}=13.88{ }^{\circ} \mathrm{C} ; T_{\text {out }}=14.61{ }^{\circ} \mathrm{C} ; P_{\text {in }}=600000 \mathrm{~Pa} ; P_{\text {out }}=3615 \mathrm{~Pa} ; Q_{m}=0.0090375 \mathrm{~kg} / \mathrm{s}$. All pressures are excessive.

Determination of the temperature at the base of the resonator was carried out by the methods of sub-modeling and iteration to select the temperature $1 / 4$ of the gas in the resonator, at which the dynamics of the temperature growth of the resonator base and its absolute value correspond to the experimental data.

Visualization of simulation results is shown in Fig.5.

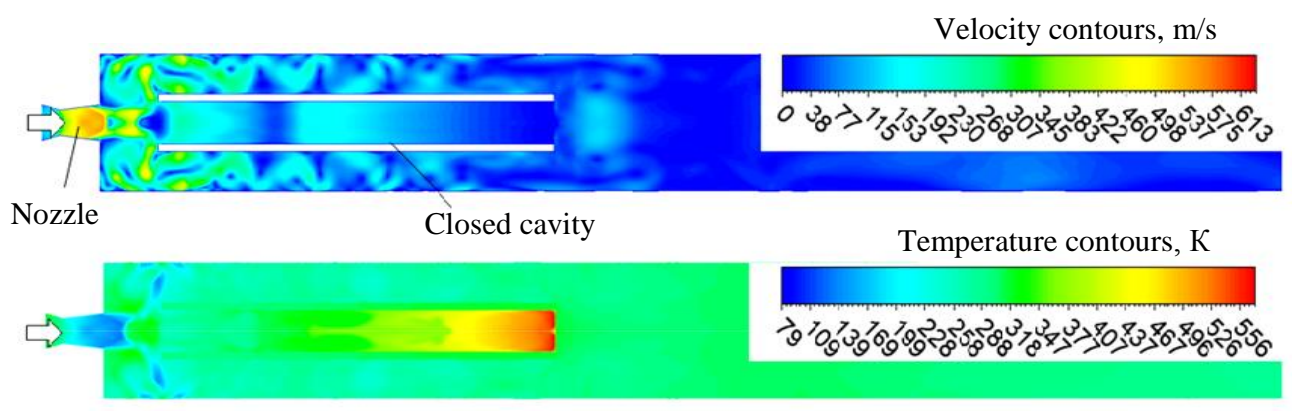

Fig.5. Temperature distribution in the resonator 
After analyzing the data obtained during the simulation and as a result of the experiment, it can be concluded that the gas temperature in the resonator during the operating mode of the device with the current configuration is from 467 to $556 \mathrm{~K}$ or from 194 to $283{ }^{\circ} \mathrm{C}$.

The main goal was achieved - gas heating, characterized by an increase in the temperature of the resonator base during the resonance effect, with stable maintenance of the flow temperature at the outlet of the device, equal to the temperature at its inlet.

Conclusion. This paper analyzes the possibility of using fireless and unheated pressure regulators for gas distribution stations. Device for unheated reduction of natural gas based on Hartmann - Sprenger resonance effect is proposed.

Numerical simulation of Hartmann - Sprenger effect in Ansys Fluent was carried out based on the computational model. As a result, the investigated effect was qualitatively achieved. Deviation of the frequency obtained by modeling the resonance effect from the theoretical value was $1.94 \%$.

Based on the results of the theoretical analysis of methods and devices utilizing gas energy, and numerical modeling, a scheme has been developed, and an experimental unit of a device for unheated natural gas reduction has been manufactured. Experiments to confirm the resonance effect with heating the gas and maintaining a given temperature at the outlet of the device have been carried out.

An indirect method using simulation in Ansys Fluent determined the gas temperature in the resonator, which is in the range from 467 to $556 \mathrm{~K}$.

Thus, in the course of this work, the possibility of using unheated pressure regulators for gas distribution stations was fully confirmed and justified. Such devices can be widely used in gas reduction points where there are risks of hydrate formation, icing of pipeline fittings and their working components. Installation of such devices will completely replace the need for burning fuel gas, which has a positive economic effect.

\section{REFERENCES}

1. Belousov A.E. Substantiation of the method for reducing natural gas in the gas distribution system using volumetric expanders: Avtoref. dis. ... kand. tekhn. nauk. St. Petersburg: Sankt Peterburgskii gornyi universitet, 2018, p. 19 (in Russian).

2. Burtsev S.A., Leontev A.I. Study of the dissipative effects influence on temperature stratification in gas flows (review). Teplofizika vysokikh temperatur. 2014. Vol. 52. N 2, p. 310-322. DOI: 10.7868/S0040364413060069

3. Vigdorovich I.I., Leontev A.I. Energy separation of gases with small and large Prandtl numbers. Izvestiya Rossiiskoi akademii nauk. Mekhanika zhidkosti i gaza. 2013. N 6, p. 117-134 (in Russian).

4. Glaznev V.N., Korobeinikov Yu.G. Hartmann effect. Region of existence and vibration frequencies. Prikladnaya mekhanika i tekhnicheskaya fizika. 2001. Vol. 42. N 4, p. 62-67 (in Russian).

5. Gurin S.V. Development of a technology for quasi-isothermal pressure reduction for objects of the natural gas transportation and distribution system: Avtoref. diss. ... kand. tekhn. nauk. Ufa: Ufimskii gosudarstvennyi aviatsionnyi tekhnicheskii universitet, 2008, p. 21 (in Russian).

6. Egorov K.S., Rogozhinskii K.S. Numerical simulation of the influence of the gas Prandtl number and the flow pattern on the efficiency of a machineless energy separation device. Nauka i obrazovanie. MGTU im. N.E.Baumana. Elektronnyi zhurnal. 2015. N 10, p. 21-35. DOI: 10.7463/1015.0814490 (in Russian).

7. Zditovets A.G., Vinogradov Yu.A., Strongin M.M. Experimental study of machineless energy separation of air flows in a Leontiev tube. Teplovye protsessy v tekhnike. 2015. Vol. 7. N 9, p. 397-404 (in Russian).

8. Ivanov I.E., Kryukov I.A., Shustov S.A. Numerical study of gas dynamics for small-sized gas generator nozzles and jets flowing from them. Vestnik Samarskogo universiteta. Aerokosmicheskaya tekhnika, tekhnologii i mashinostroenie. 2014. Vol. 13. N 1, p. 112-122. DOI: 10.18287/1998-6629-2014-0-1(43)-112-122 (in Russian).

9. Isaev S.A., Leontiev A.I., Kornev N.V. et al. Intensification of heat transfer in laminar and turbulent flow in a narrow channel with single-row oval dimples. Teplofizika vysokikh temperatur. $2015 . \quad$ Vol. 53. N3, p. $390-402$. DOI: $10.7868 /$ S0040364415030060 (in Russian).

10. Kataev K.A. Hydrate formation in natural gas pipelines. Vserossiiskii zhurnal nauchnykh publikatsii. 2011. N 1(2), p. 22-23 (in Russian).

11. Sizyakov V.M., Gradov D.V., Turunen I., Laari A. Computer simulation of physical processes in a gas-liquid reactor. Journal of Mining Institute. 2013. Vol. 202, p. 284-287 (in Russian).

12. Kuligin P.A. Use of innovative technologies to achieve energy efficiency and energy saving - the path to energy security of the country. Journal of Mining Institute. 2011. Vol. 191, p. 121-124 (in Russian).

13. Li Chzhun Min. Investigation of thermoacoustic heating of gas in Hartmann gas-jet generators: Avtoref. dis. ... kand. tekhn. nauk. Moscow: Moskovskii aviatsionnyi institut, 2004, p. 22 (in Russian). 
14. Makarov M.S., Makarova S.N. Efficiency of energy separation in a compressible gas flow in a flat channel. Teplofizika $i$ aeromekhanika. 2013. Vol. 20. N 6, p. 777-787 (in Russian).

15. Varaksin A.Yu., Romash M.E., Kopeitsev V.N., Gorbachev M.A. Method of influencing free non-stationary air vortices. Teplofizika vysokikh temperatur. 2012. Vol. 50. N 4, p. 533-537. DOI: 10.1134/S0018151X12040219 (in Russian).

16. Musakaev N.G., Urazov R.R. Preventive methods to counter hydrate formation in pipelines. Izvestiya vysshikh uchebnykh zavedenii. Neft i gaz. 2006. N 1, p. $50-56$ (in Russian).

17. Parfenov D.V. Prevention of heating elements in valve nodes when filling with gas sections of trunk gas pipelines: Avtoref. dis. ... kand. tekhn. nauk. Ukhta: Ukhtinskii gosudarstvennyi tekhnicheskii universitet, 2018, p. 18 (in Russian).

18. Leontev A.I. Patent N 2106581 RF. Method for temperature stratification of gas and device for its implementation (Leontief tube). Publ. 10.03.1998. Bul. N 7 (in Russian).

19. Belousov A.E., Kabanov O.V. Patent N 2620624 RF. Expander-generator unit with its control system. Publ. 29.05.2017. Bul. N 16 (in Russian).

20. Belousov A.E., Dmitrieva A.S., Shchipachev A.M. Patent N 2737214 RF. Thermoacoustic pressure regulator. Publ. 26.11.2020. Bul. N 33 (in Russian).

21. Pashkevich M.A., Movchan I.B., Petrova T.A. Monitoring of technogenic impact of environmentally hazardous facilities of OJSC “Gazprom”. Journal of Mining Institute. 2007. Vol. 172, p. 201-204 (in Russian).

22. Petrova T.A. Monitoring of technogenic impact of environmentally hazardous facilities of OJSC "Gazprom". Journal of Mining Institute. 2013. Vol. 203, p. 205-208 (in Russian).

23. Popovich S.S. Influence of shock waves on the effect of machineless energy separation: Avtroef. dis. ... kand. tekhn. nauk. Moscow: Nauchno-issledovatel'skii institut mekhaniki MGU im. M.V.Lomonosova, 2016, p. 21 (in Russian).

24. Repin L.A. Possibilities of using natural gas pressure energy at small gas distribution stations. Energosberezhenie. 2004. N 3, p. 34-39 (in Russian).

25. Fokin G.A. Methodology for the creation of autonomous turbine sources of electrical energy using compressed natural gas energy for the own needs of the gas transportation system of Russia: Avtoref. dis. ... d-ra tekhn. nauk. St. Petersburg: Sankt Peterburgskii politekhnicheskii universitet Petra Velikogo, 2015, p. 40 (in Russian).

26. Khazov D.E. Numerical study of machineless energy separation of the air flow. Teplovye protsessy v tekhnike. 2018. Vol. 10. N 1-2, p. 25-36 (in Russian).

27. Khait A.V. Study of the energy separation effect in order to improve the characteristics of a vortex tube: Avtoref. dis. ... kand. tekhn. nauk. Ekaterinburg: Uralskii federalnyi universitet imeni pervogo Prezidenta Rossii B.N.Eltsina, 2012, p. 20 (in Russian).

28. Tsynaeva A.A., Tsynaeva E.A., Nikitin M.N. Intensification of heat transfer in energy devices based on gas-dynamic temperature stratification using heat pipes. Promyshlennaya energetika. 2014. N 12, p. 36-39 (in Russian).

29. Chernykh A.S., Karasevich V.A., Yakovlev A.A. Prospects for the use of autonomous energy sources in the transportation and distribution of gas. Nauchnyi zhurnal rossiiskogo gazovogo obshchestva. 2016. N 1, p. 59-61 (in Russian).

30. Savchenkov S.V., Aginei R.V., Repin D.G. et al. Numerical simulation in ANSYS CFX of the heating phenomenon for dead-end branches of valve nodes. Gazovaya promyshlennost. 2013. N 10, p. 13-16 (in Russian).

31. Shubin A.V., Dmitrieva A.S., Belousov A.E. Implementation of an energy separating device based on the Hartmann Sprenger effect into the reduction unit of a gas distribution station equipped with an expander-generator. Trudy nauchnoprakticheskoi konferentsii s mezhdunarodnym uchastiem "Inzhenernye sistemy - 2019", 3-5 aprelya 2019, Moskva, Rossiya. Rossiiskii universitet druzhby narodov, 2019, p. 411-420 (in Russian).

32. ShushinN.A. About gas heating during throttling. Izvestiya vysshikh uchebnykh zavedenii. Aviatsionnaya tekhnika. 2011. N 4, p. 67-69 (in Russian).

33. Shchipachev A.M., Belousov A.E., Dmitrieva A.S. Increasing the efficiency of natural gas reduction at gas distribution stations. Delovoi zhurnal Neftegaz.RU. 2020. N 3(99), p. $92-96$ (in Russian).

34. Azanov G.M., Osiptsov A.N. The efficiency of one method of mashineless temperature stratification in a gas flow. International Journal of Heat and Mass Transfer. 2017. Vol. 106, p. 1125-1133. DOI:10.1016/j.ijheatmasstransfer.2016.10.090

35. Eiasma-ard S., Promvonge P. Review of Ranque - Hilsch effects in vortex tubes. Renewable and Sustainable Energy Reviews. 2008. Vol. 12. Iss. 7, p. 1822-1842. DOI: 10.1016/j.rser.2007.03.006

36. Bell I.H., Wronski J., Quoilin S., Lemort V. Pure- and pseudo-pure fluid thermophysical property evaluation and the opensource thermophysical property library cool prop. Industrial \& Engineering Chemistry Research. 2014. Vol. 53. Iss. 6, p. $2498-2508$. DOI: $10.1021 / \mathrm{ie} 4033999$

Authors: Andrei M.Schipachev, Doctor of Engineering Sciences, Professor, schipachev_am@pers.spmi.ru, https://orcid.org/0000-0001-6148-6073 (Saint Petersburg Mining University, Saint Petersburg, Russia), Alena S. Dmitrieva, Postgraduate Student, alena_dmitrieva57@rambler.ru, https://orcid.org/0000-0002-1180-3226 (Saint Petersburg Mining University, Saint Petersburg, Russia).

The authors declare no conflict of interests.

The paper was received on 17 March, 2021.

The paper was accepted for publication on 29 March, 2021. 